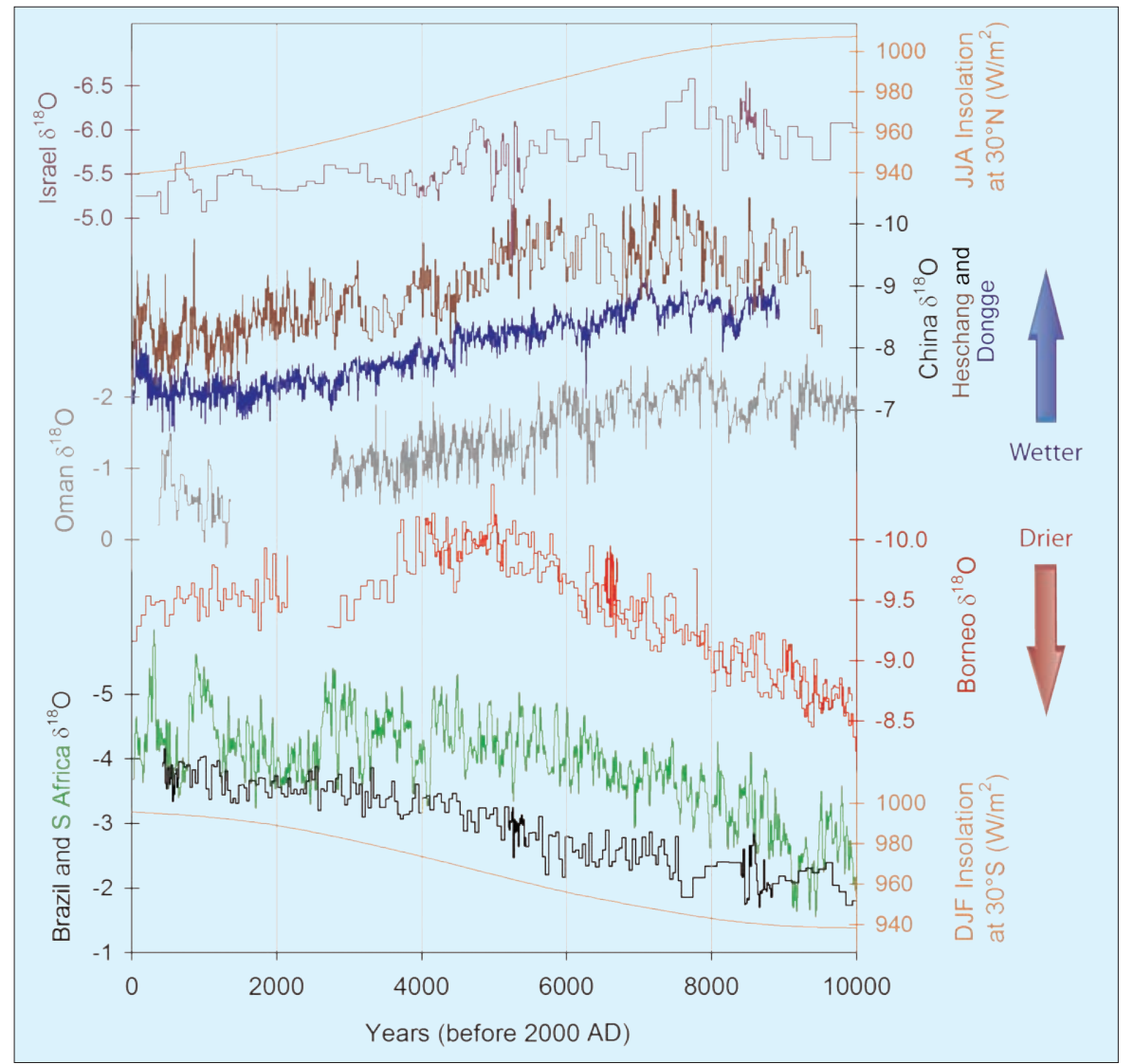

Figure 2: Speleothem $\delta^{18} \mathrm{O}$ records for the last $10 \mathrm{kyr}$ arranged from $N$ to S., Soreq Cave, Israel (purple); Heshang Cave, China (brown); Dongge Cave, China (blue); Qunf Cave, Oman (gray); Snail Shell and Bukit Assam Caves, N. Borneo (red); Cold Air Cave, S. Africa (green); Botuverá Cave, Brazil (black). Also plotted are summer insolation curves at $30^{\circ} \mathrm{N}$ (top) and $30^{\circ} \mathrm{S}$ (bottom) (orange curves). Wetter conditions correspond to smaller $8^{18} \mathrm{O}$ values and drier conditions larger $\delta^{18} \mathrm{O}$ values via the "amount effect" (note that axes are reversed).

changes in insolation, and the need for additional records from the deep tropics.

Speleothems also offer the opportunity to determine the magnitude and absolute timing of terrestrial climate changes with records that contain sub-annual- to decadal-resolution. This characteristic makes them invaluable for the study of abrupt climate change. For example, a landmark speleothem record from China links abrupt changes in the Asian Monsoon to abrupt climate changes recorded in the Greenland ice cores (Wang et al., 2001). The speleothem records from China have recently been extended to $224 \mathrm{kyr}$ at a temporal resolution of $\sim 40-70$ years (Wang et al., 2008). These extraordinary records highlight the ability of speleothems to provide climate information past MIS 5, beyond the limit of the Greenland ice cores. Speleothem records will continue to provide key constraints on the geographical extent to which abrupt climate changes affect precipitation over land.

While this article does not represent an exhaustive review of speleothem records, the small compilation of Holocene speleothem records shown in Figure 2 highlights the potential of constructing a global database of speleothem records that could be used to address a variety of paleoclimate challenges. Tree ring databases for the United States are a standard that speleothem records should try to attain; high spatial coverage at high temporal resolution over a long time period. Many authors have developed speleothem records across the globe from $100 \mathrm{kyr}$ until present, however many gaps still exist. Also needed are companion calibration studies that enhance the climatic interpretation of the stalagmite records. Speleothem records show how the hydrologic cycle is affected by external forcing, as well as how natural climate variability impacts largescale precipitation patterns. These past changes in the hydrologic cycle have important consequences for water resource planning today as they define the range that planners should consider.

\section{Note}

The websites for data from Soreq Cave (Israel), Heshang and Dongge Caves (China), Qunf Cave (Oman), Snail Shell and Bukit Assam Caves (N. Borneo), Botuverá Cave (Brazil), and Cold Air Cave (S. Africa), can be found at www.pagesigbp.org/products/newsletters/ref2008_3.html

\section{References}

Fleitmann, D., Burns, S.J., Mudelsee, M., Neff, U., Kramers, J., Mangini, A. and Matter, A., 2003: Holocene forcing of the Indian monsoon recorded in a stalagmite from Southern Oman, Science, 300: 1737-1739.

Partin, J.W., Cobb, K.M., Adkins, J.F., Clark, B. and Fernandez, D.P., 2007: Millennial-scale trends in Warm Pool hydrology since the Last Glacial Maximum, Nature, 449: 452-455.

Treble, P., Shelley, J.M.G. and Chappell, J., 2003: Comparison of high resolution sub-annual records of trace elements in a modern (1911-1992) speleothem with instrumental climate data from southwest Australia, Earth and Planetary Science Letters, 216 141-153.

Wang, X., Auler, A.S., Edwards, R.L., Cheng, H., Ito, E. and Solheid, M. 2006: Interhemispheric anti-phasing of rainfall during the last glacial period, Quaternary Science Reviews, 25: 3391-3403.

Wang, Y.J., Cheng, H., Edwards, R.L., An, Z.S., Wu, J.Y., Shen, C.C. and Dorale, J.A., 2001: A high-resolution absolute-dated Late Pleistocene monsoon record from Hulu Cave, China, Science, 294 2345-2348.

\title{
Paleotemperature reconstruction using noble gas concentrations in speleothem fluid inclusions
}

\section{Yvonne Scheidegger ${ }^{1,2}$, T. Kluge ${ }^{3}$, R. Kipfer ${ }^{1,2}$, W. Aeschbach-Hertig ${ }^{3}$ And R. Wieler ${ }^{1}$}

${ }^{1}$ Isotope Geochemistry and Mineral Resources, Swiss Federal Institute of Technology, ETH Zurich; yvonne.scheidegger@eawag.ch ${ }^{2}$ Water Resources and Drinking Water, Swiss Federal Institute of Aquatic Science, Eawag; ${ }^{3}$ nnstitute for Environmental Physics, University of Heidelberg, Germany.

Stalagmites are gaining importance in paleoclimate research as they provide highresolution stable isotope signals over glacial-interglacial timescales. The major difficulty in the interpretation of stalagmite oxygen and carbon isotope data is to disentangle the various effects and processes that control the signals. One important parameter is the mean air temperature in the cave. Cave temperatures remain relatively constant throughout the year at approx. the local mean air temperatures. Accordingly, paleotemperature reconstructions from cave deposits provide good estimates of the past annual mean outside the cave (McDermott, 2004; Genty et al., 2002). However, there is a lack of tools for direct determination of cave paleotemperatures. Noble gases dissolved in water inclusions can provide this informa- 


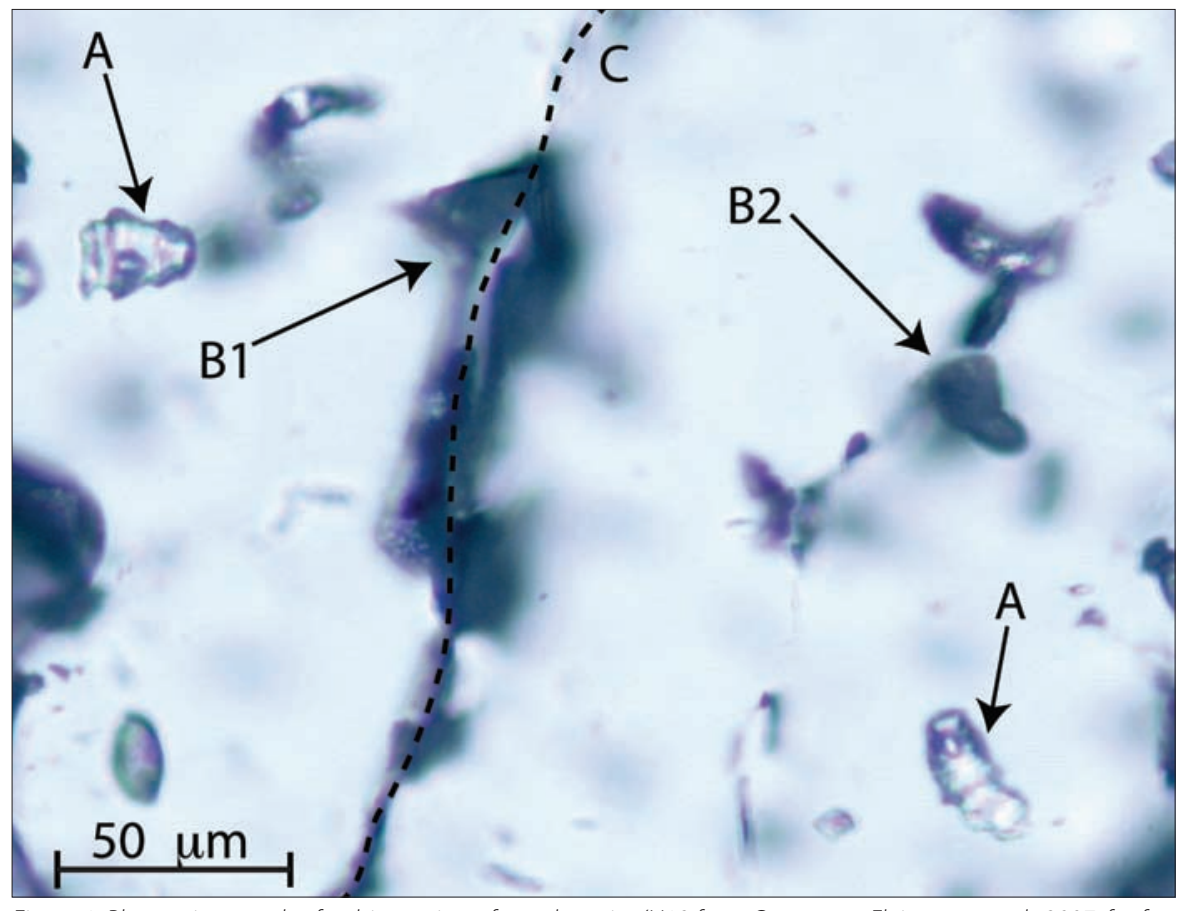

Figure 1: Photomicrograph of a thin section of a stalagmite (H12 from Oman; see Fleitmann et al., 2007, for further details). A: Intra-crystalline water inclusions (with an air bubble), B1: Inter-crystalline air inclusion, B2: Intracrystalline air inclusion, $\mathrm{C}$ : Grain boundary.

tion, as they are a direct proxy of the temperature during air-water partitioning.

\section{Noble gas thermometer}

The concentrations of dissolved noble gases ( $\mathrm{He}, \mathrm{Ne}, \mathrm{Ar}, \mathrm{Kr}, \mathrm{Xe})$ in water depend on the atmospheric pressure (i.e., the altitude), as well as the temperature and salinity of the water at the time of its last contact with air (i.e., during the entrapment of fluid inclusions in stalagmites). Using the well-established noble-gas concepts employed in lakes and groundwater (e.g., Aeschbach-Hertig et al., 2000; Kipfer et al., 2002), the concentrations of dissolved atmospheric noble gases in water inclusions provide a noble-gas archive that allows the direct and quantitative reconstruction of past cave temperatures.

During stalagmite growth, minute quantities of drip water and cave air are any information about past climate conditions. Thus, for a successful determination of noble gas temperatures (NGTs), the gases originating from water inclusions have to be separated from those liberated from air inclusions, to reduce the amount of "excess air" ("excess" noble gases from one phase air inclusions and/or air bubbles in water inclusions).

Secondly, noble gas concentrations are required for the calculation of NGTs, therefore the amount of water extracted from the sample has to be known with high precision. These amounts are typically about $1 \mu \mathrm{l}$, thus for an average noble gas analysis, relatively large stalagmite samples of ca. $1 \mathrm{~cm}^{3}$ are needed, leading to an average temporal resolution of ca. 100 years (average growth rate of $50 \mu \mathrm{m}$ ).

\section{Extraction of noble gases}

For stalagmites with a high water content and low abundance of air inclusions, noble gases are extracted in a single crushing step. The stalagmite sample is crushed under vacuum in a crusher consisting of a stainless steel cylinder, with a polished steel ball inside that can be moved manually by a permanent magnet placed around the cylinder.

For stalagmites with a higher abundance of air inclusions $\left(\mathrm{V}_{\text {air }} / \mathrm{V}_{\text {water }} \sim 1\right)$, a single crushing step leads to a high amount of excess air. This excess air masks the noblegas signature of the water, thus making it very difficult to calculate NGTs. In this case, stepwise extraction techniques are more suitable. Figure $2 a$ and $b$ show the results of stepwise crushing and stepwise heating (with an initial crushing step) experiments, respectively. Several subsequent extraction steps, by either heating or crushing, lead to noble gas signatures that are closer to air-saturated water and lead to a significant reduction of excess air (from $\mathrm{V}_{\text {air }} / \mathrm{V}_{\text {water }}$

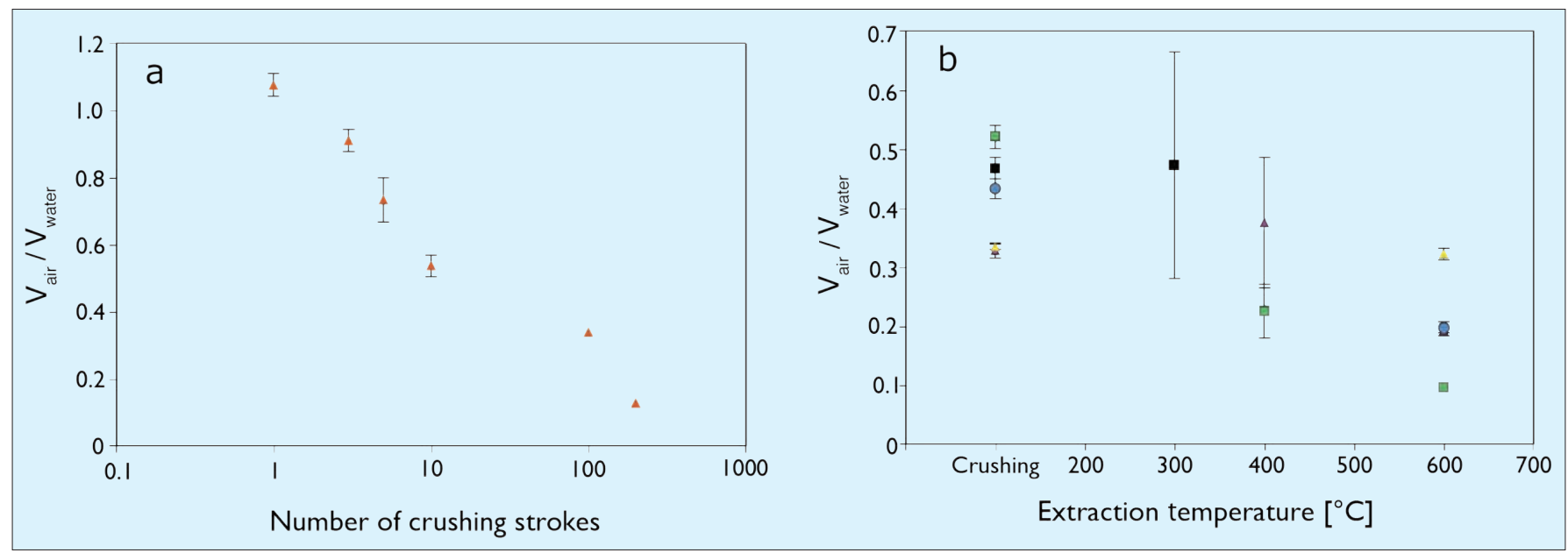

Figure 2: Results of $(\boldsymbol{a})$ stepwise crushing and (b) stepwise heating experiments used to reduce the effect of "excess air". $\boldsymbol{a}$ ) Air-water volume ratio ( $V$ air $/ V$ wate) of a piece from the H12 stalagmite (Oman) displayed against the number of crushing strokes. $V_{\text {air }} / V_{\text {water }}$ was reduced by about one order of magnitude using the stepwise crushing extraction. $\boldsymbol{b}) \mathrm{V} / \mathrm{V}$ of several stalagmite samples (indicated by different symbols) after an initial crushing step followed by one or several heating steps. Using this technique the value of $V_{\text {air }} / V_{\text {water }}$ can be substantially reduced (data from Scheidegger, 2005). 


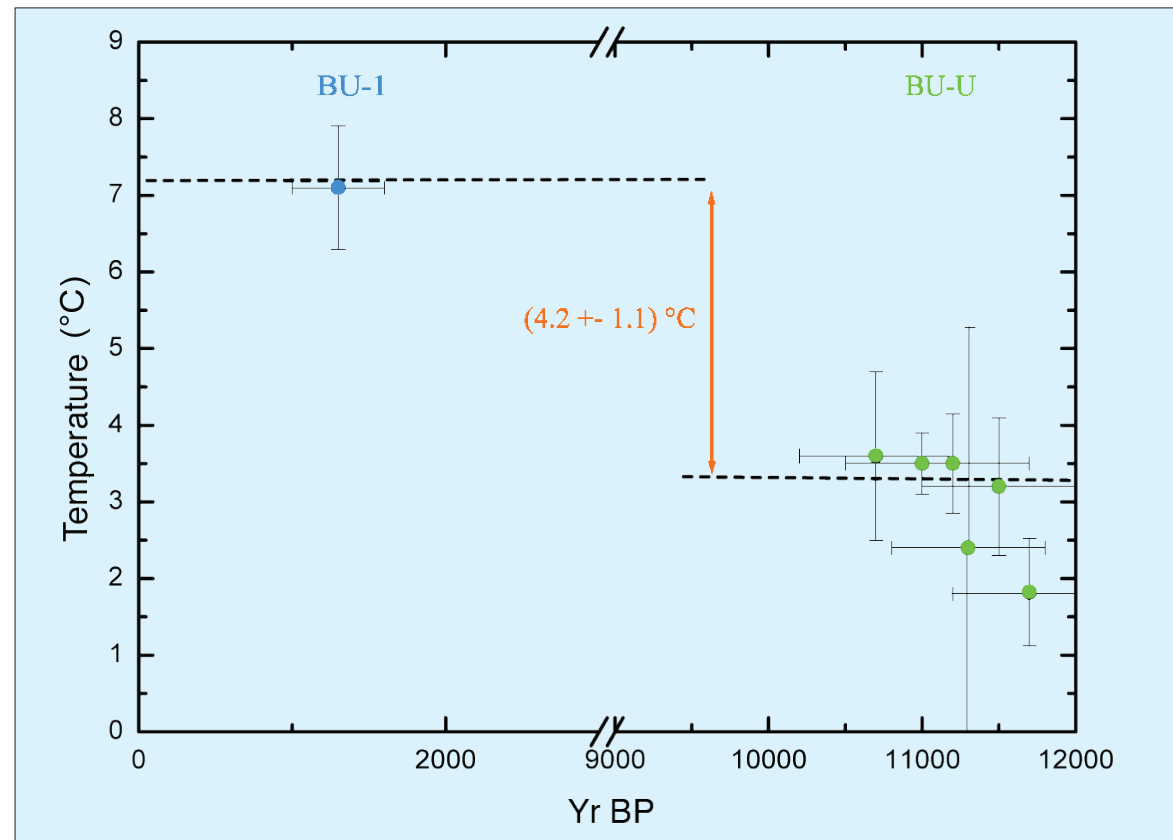

Figure 3: Noble gas temperatures calculated for a sample from a 1300-yr-old stalagmite BU-1 and six sub-samples from an early Holocene stalagmite $B U-U$.

$>1$ to $\left.\mathrm{V}_{\text {air }} / \mathrm{V}_{\text {water }}<0.3\right)$. For both extraction methods, the amount of the liberated water is determined manometrically. At ETHZurich, the pressure of the water vapor is measured in an accurately known volume and at a well-defined temperature provided by a water bath. This system allows calculation of water amounts in the range of $1 \mathrm{mg}$ with a precision of $1.5 \%$. In Heidelberg, known amounts of water prepared in capillaries are used to calibrate the system. With this procedure, a precision of about $2 \%$ is achieved.

\section{Paleotemperatures}

In order to derive temperatures from the determined noble gas concentrations, inversion techniques, as developed for groundwater (Aeschbach-Hertig et al., 1999), can be used. It is assumed that stalagmites contain noble gases originating from air-saturated water (water inclusions) and atmospheric air (air inclusions and/or air bubbles in water inclusions). Samples from Bunker Cave (NW Germany) confirm this assumption. In this case, the simple extraction with only a single crushing step is adequate to determine
NGTs with a typical uncertainty of about $1^{\circ} \mathrm{C}$ (Kluge et al., 2008). Six sub-samples have been extracted from the uppermost $\mathrm{cm}$ of the stalagmite BU-U from the Bunker Cave, which belongs to one growth layer with an U-Th age of 10.8 to $11.7 \mathrm{kyr}$ BP. They yielded reproducible values with a mean of $2.9 \pm 0.7^{\circ} \mathrm{C}$. Although different extraction procedures and measurement methods have been used, e.g., squeezing in copper tubes and crushing in a steel cylinder, the calculated temperatures all fall within the range of uncertainties (Fig. 3). The considerably younger sample from another Bunker Cave stalagmite (BU1), extracted at $5 \mathrm{~cm}$ distance from the top, with an U-Th age of $1300 \pm 300 \mathrm{yr} B P$, resulted in a higher temperature of $7.1 \pm 0.8^{\circ} \mathrm{C}$. Thus, the noble-gas-derived temperature difference between samples from the early Holocene (BU-U) and the early Middle Ages (BU-1) was found to be about $4^{\circ} \mathrm{C}$ (Fig. 3). This agrees well with results from other studies in this region (Davis et al., 2003).

Noble gas concentrations of several samples from other caves, however, show noble gas signatures that are distinct from those expected by a simple mixture of no- ble gases from air and air-saturated water. Modern stalagmites from caves in Yemen and Oman (Fleitmann et al., 2007) show strong fractionations due to an enrichment in the light noble gases $(\mathrm{He}, \mathrm{Ne}$ ) and partly also in xenon. These results show that the noble gas signatures cannot be explained, in all cases, by a simple mixture of noble gases from air and air-saturated water alone, indicating that the entrapment of water inclusions in the growing stalagmite may be more complicated than initially assumed. For several samples from Yemen, calculated NGTs lie in the range of the modern cave temperature $\left(27^{\circ} \mathrm{C}\right)$, but errors are large $\left(3-6^{\circ} \mathrm{C}\right)$ due to the fractionated noble gas signature.

Our results indicate that the determination of NGTs in stalagmites is, in principle, possible. For samples with a very low value of $\mathrm{V}_{\text {air }} / \mathrm{V}_{\text {water }}\left(\mathrm{V}_{\text {air }} / \mathrm{V}_{\text {water }}<0.1\right)$, noble gases are clearly a mixture of air and airsaturated water and therefore NGTs can be calculated with a precision of about $1^{\circ} \mathrm{C}$. For other samples, more sophisticated, stepwise extraction techniques that are currently being tested may strongly reduce the value of $\mathrm{V}_{\text {air }} \mathrm{N}_{\text {water }}$ by separating air and water inclusions more quantitatively. These techniques are thus expected to increase the number of samples suitable for NGT determination in the future.

\section{References}

Aeschbach-Hertig, W., Peeters, F., Beyerle, U. and Kipfer, R., 2000: Palaeotemperature reconstruction from noble gases in ground water taking into account equilibration with entrapped air, Nature, 405: 1040-1044

Kipfer, R., Aeschbach-Hertig, W., Peeters, F. and Stute, M., 2002: Noble gases in geochemistry and cosmochemistry. In: D. Porcelli, et al, (Eds), Reviews in Mineralogy and Geochemistry, Mineralogical Society of America, Geochemical Society, 47: 615-700.

Kluge, T., Marx, T, Scholz, D., Niggemann, S., Mangini, A. and AeschbachHertig, W., 2008: A new tool for palaeodimate reconstruction: Noble gas temperatures from fluid inclusions in speleothems, Earth and Planetary Science Letters, 269: 407-414.

Scheidegger, Y., 2005: Stalagmiten als mögliche Klimaarchive, Unpublished diploma thesis, ETH Zürich.

Scheidegger, Y., Badertscher, S.V., Driesner, Th., Wieler, R., Heber, V.S. and Kipfer, R. 2007: Microscopical speleothem calcite investigations proofing the existence of two different types of fluid inclusions, Geophysical Research Abstracts (EGU, Vienna).

\section{Future looking gloomy? Need a new challenge?}

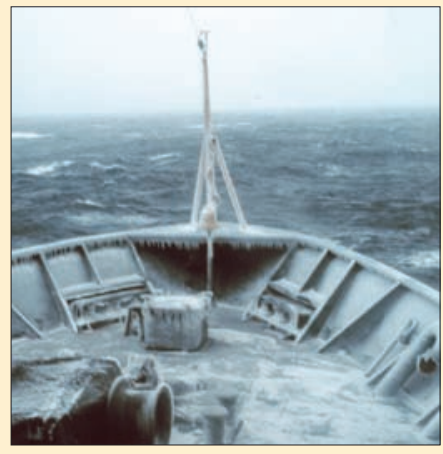

\section{Try PAGES free Jobs Database!}

\section{All the international paleoscience jobs from listservers in the one place.}

Harvested Listservers:

AQUAlist, Arcticlnfo, CLIMLIST, CRYOLIST, Paleoclimate, Paleolimnology, PaleoNet, Sclerochronology.

Browse or add jobs at: www.pages-igbp.org/services/jobs/ 